\title{
Financial Support for Technological Innovation of the Supply-Side Reform
}

\author{
Jiaqing Deng \\ Institute of Industrial Economics, Jinan University, Guangzhou, China \\ Email:69838463@qq.com
}

How to cite this paper: Deng, J.Q. (2017) Financial Support for Technological Innovation of the Supply-Side Reform. Open Journal of Social Sciences, 5, 159-171. https://doi.org/10.4236/jss.2017.53014

Received: February 13, 2017

Accepted: March 19, 2017

Published: March 22, 2017

Copyright (C) 2017 by author and Scientific Research Publishing Inc. This work is licensed under the Creative Commons Attribution International License (CC BY 4.0).

http://creativecommons.org/licenses/by/4.0/

\begin{abstract}
Innovation is inseparable from the development of enterprise and the improvement of enterprises, and the improvement of innovation is inseparable from the supporting system. In the background of advocating supply-side reform in our country, this paper examines the adjustment of elements structure in the supply-side reform, by constructing models to analyze the need of money when enterprises decided to invest in innovation as well as how financial system affects their need. The result of the model shows that the interest rate of loan determinates whether the company decides to undertake technological innovation. Indirect financing market can stimulate enterprises' $R \& D$ through powering down the risk premium; direct financing market can promote $R \& D$ investment by adjusting the ratio between interest rate and riskless interest rate.
\end{abstract}

\section{Keywords}

Supply-Side Reform, Technological Innovation, Indirect Financing

\section{Introduction}

The 11th meeting of the CPC Central Leading Group for Financial and Economic Affairs held on November 10, 2015 brings out a reform policy to achieve the overall jump of the social productivity, which stresses the supply-side reform, the improvement of quality and efficiency of supply system, and the promotion of continuous driving force of economy while properly enlarge the aggregate demand. The word "supply-side reform" has frequently come into people's life. For a long time, macro-regulation on supply-side featured by "investment, expense and exportation" has materialized China's steady economic growth. At the same time, new difficulties arise. Supply-side structural reform faces the problems of how to transfer excess manufacturing capacity, how to reduce enterprise cost, how to consume local inventory, and how to ward off fi- 
nancial risks. This paper takes the approach of reducing excess manufacturing capacity and elevating total factor productivity to analyze the financial support to an enterprise during innovation process within supply-side reform.

This paper is organized as follows. Section 2 reviews the relevant literature. Section 3 analyzes the cost of innovation and the impact of financing system on enterprise innovation by establishing two models. Section 4 concludes.

\section{Literature Review}

Some domestic researchers study on supply-side structural reform. Labor, earth, capital and innovation are the four elements of the supply side, which emphasise the self-regulation of market, through which the elements can achieve optimal configuration, thus further elevate the quality and quantity of economy growth (Ming Wu, 2016) [1]. Xiahui Liu (2016) [2] points out that supply-side reform is not to increase manufacturing capacity, but to reorganize production and the market more effectively, to elevate output efficiency and try to balance supply and demand. The focus should be on raising the efficiency and quality of supply element. Lei Deng and Shuang Du (2015) [3] think that China's supply-side reform is a structural one, including the reform of structure of production factors, industrial structure, and the main structure of supply and so on. Zhifeng Feng (2016) [4] takes that "supply-side structural reform" is the reform of structure in three aspects of institution, mechanism and technology on the supply side. He iterates that it is a reform on supply instead of production, and the focus is to reduce institutional transaction costs since high cost is the fatal weakness on the supply side. Zhi Li and Xifeng Yuan (2016) [5] believe by means of reducing government cost, cutting tax revenue, and expanding privatization, supply-side reform can strengthen market competition, release element vigor, lift supply constraint and promote economic growth and social prosperity. Kangning Xu (2016) [6] stresses a good use of market mechanism and government tax reduction should be made to improve the supply of production factors, thus optimizes supply structure and expands efficient supply. Some like Angang $\mathrm{Hu}$ (2016) [7] put forward a way to combine "four arithmetic operations" and "five pillar policies" with Chinese characteristics. Chong Li [8] holds that while conducting long-term practices, short-term reform may also be taken into account. Hongju Wang (2016) [9] and some others study the backdrop of the international economic cycle mismatch and point out macro-policy should be supportive on the supply side as the reform deepens in China. Some like Weibing Lin (2016) [10] hold that supply-side reform is to adjust China's macro-economy management from two aspects, namely stressing supply management and altering the way of administrative supply management. Yuhong An (2016) [11] suggests the reform should be conducted on industry, scheduling, fiscal and taxation system and capital levels.

Supply-side reform is reflected by the performance of encouraging enterprise innovation, speeding up the elimination of backward production capacity and promoting economic development. Many foreign scholars study the innovation 
activities. Innovation is an important impetus for economy growth (Aghion \& Howitt, 1992; Romer, 1990) [12] [13]. Such activities bear the following characteristics: first, innovation has positive spillover effect, thus the best performance of a single enterprise is below that of the whole society, suggesting that the cost of basically all innovative adjustments is high. In fact, around $50 \%$ of the money goes to the payment of highly-skilled workers, highly educated scientists, engineers and other special researchers, whose employment, dismiss and training are all big budgets (Hall \& Lerner, 2010) [14]. If some of the dismissed experts get employed by the rivals, the loss will be more than the training fees as they can imitate the invention and benefit from the valuable knowledge transmitted. Second, innovative activity has much uncertainty as the precise value of the mortgage is not available. Some innovation patents, like new designs, cannot easily be taken as mortgage for the innovative procedures are usually practiced within certain companies whose production technology is usually backward (Hall, 1992) [15]. Third, the input for innovation cannot be retrieved. The first stage input all goes into the purchase the special equipment, material and researcher's payment (Dixit \& Pindyck, 1994) [16]. Four, it is hard to estimate the long-term payback and possible market influence. As innovative activities are mostly long-turn projects, an enterprise is not sure how much effort and material is required (Pindyck, 1993) [17], the market demand and acceptability also remain unknown.

Some foreign scholars also analyze the factors of innovation. The first is the asymmetry of information. The enterprise with innovative ideas bears more information than the exterior investor on success probability and expected return, which may lead to low market efficiency. So does the statistical method used in calculating R\&D expenditure. Asymmetric information puts both dealers in imbalanced state, which may raise the cost of exterior capital-raising. As a result, lenders may require higher return for the uncertainty of the borrower's payback ability, which means the amount of loans cannot be balanced under market interest rate. Besides, the existence of organized innovation market aggravates the asymmetry. The second is adverse selection. Since exterior investors cannot estimate the right and wrongs of new ideas, some potential investors may leave for fear of the high risk (Harhoff, 1998) [18]. Moreover, the amount of loan may come below the required optimal level. Conventional solutions like signal, reputation and financial intermediation may be of no avail to those innovation-intense enterprises (Takalo \& Tanayama, 2011) [19].

Many scholars both at home and abroad also study the support of financial system to independent innovation enterprises. A group represented by Saint (1992) [20] contends that the completion degree of financial system exerts notable influence on these enterprises. With more advanced financial system, especially when it works highly efficiently, enterprise may put the riskier and more innovative technology into production. Benfratello et al. (2008) [21] notes that for independent innovation enterprises, raising fund through financial intermediation can reduce the fluctuation in cash flow, which better secures a steady 
influx of R\&D funding. Harhoff (1998) [18] \& Hall $(1992,2009)$ [15] say constraint on the liberal market adds pressure to fund raising for R\&D activities. Banks are usually risk-averse, which tend to loan to less risky projects, so that they can conduct relevant external supervision more effectively (Fama, 1985; Dattaet et al., 1999) [22] [23]. Enterprises can get debt funding with collateral mortgage from the bank (Berger \& Udell, 1990) [24]. Optimal bank loan can further secure investment efficiency while politics-based soft loan, influenced by their investment decision, may have prejudice on company behavior (Chen et al., 2011) [25]. Guohua $\mathrm{He}$ (2011) [26] analyses how indirect fund raising influence the ability to conduct independent innovation in 31 provinces in China during the span from 1997 to 2009 . He thinks there is significant positive effect between the two. Yaoming Ye (2007) [27] notes that loan offered by financial intermediation and funding raised through stocks and bonds are the major source of the needed capital for technology innovation.

\section{Basic Model}

According to the production function $Y=f(L, K, A)^{1}$ in economic growth theory, an increase of total factor productivity can promote economy growth. $A$ is usually affected by factors like institution, technology, natural conditions. Model 1 and model 1e take the approach of optimize technology innovation to discuss financing cost; model 2 and model 2e take the approach of institutional transaction cost to analyze the influence of financing system decision on innovation investment of enterprises.

\section{Model 1 Investment Decision on Enterprise Innovation}

First, in a perfect competitive commodity market, whether to invest in innovation R\&D depends on how much of the elevated utilization of production factors from supply-side reform can be used.

If an enterprise is successful in new technology investment, there are two possible results: one is open source effect, namely to have the right to a higher price in the market; the other is throttle effect, which is to trim the cost. At the point $t=0$ (Figure 1), supposing the enterprise has no fixed cost, the maximum profit will be:

$\begin{array}{lll}\begin{array}{l}\text { Before the decision, } \\ \text { the enterprise chooses }\end{array} & \begin{array}{l}\text { The enterprise } \\ \text { decide whether } \\ \text { production } y \text { to }\end{array} & \begin{array}{l}\text { After technology innovation, } \\ \text { open source effect and } \\ \text { throttle effect may take place. }\end{array} \\ \begin{array}{l}L W_{0} \text { as research } \\ \text { (namely the wealth) }\end{array} & \begin{array}{l}\text { As for the former, the result } \\ \text { funding } I \text { to realize } \\ \text { technology }\end{array} & \begin{array}{l}\text { will be } \tilde{p}=\omega p, \text { in which the } \\ \text { probability of success is } \theta L / \bar{L}\end{array} \\ & \text { progress } & \begin{array}{l}\text { and accordingly the } \\ \text { probability of failure will be } \\ 1-\theta L / \bar{L}\end{array}\end{array}$

Figure 1. The process of enterprise innovation investment.

${ }^{1} Y$ is total output; $f(\cdot)$ is a function expression; $L$ is labor input; $K$ is capital stock; $A$ is total factor productivity. 


$$
\max _{y} p y-\frac{1}{2} c y^{2}
$$

$p$ is the price on market, $c$ is the variable cost coefficient of the enterprise. Therefore:

$$
y^{*}=\frac{p}{c}
$$

So when $t=0$ (Figure 1 ), the wealth is:

$$
W_{0}^{*}=\frac{p^{2}}{2 c}
$$

When $t=1$ (Figure 1), the enterprise decide whether to invest in $\mathrm{R} \& \mathrm{D}$ based on the equation of $I=W_{0}(1+L)$, in which $L$ is the ratio between the number of loans and their initial wealth $(0<L \leq \bar{L})$. Concerning the influence of financial structure, there is $L>0$, which implicates that R\&D expense is more than the capital an enterprise has in hand. For $L \leq \bar{L}$, the budget of the chosen $R \& D$ activity cannot exceed a certain ratio of the original wealth. To simplify the problem, external loans from the bank is supposed to have a certain total interest rate as $r$. If when $t=2$ (Figure 1), the enterprise invests, the market price will turn into $\tilde{p}=\omega p$, in which $\omega$ is the margin of price increase ("open source effect"). When the probability of success is $\theta L / \bar{L}$ ( $\theta$ is the efficiency factor of the technology innovation project, depicting the increase of probability brought by adding one unit of loan), the profit is positive, and the probability of failure is $1-\theta L / \bar{L}$ accordingly. Besides, if the investment is successful, part of the cost may as well be saved ("throttle effect"). Here the discussion falls mainly on the relation between financing on technology innovation and the open source effect. Supposing after the investment, innovation is realized, and the cost becomes $\tilde{c}=\alpha c$. The margin of reduced cost is $\alpha$. If the probability of successful throttling for the enterprise is $\pi$, then $1-\pi$ is the probability of failure.

Put the above hypothesis into mathematic language, then

$$
\omega=\left\{\begin{array}{l}
\bar{\omega}, \text { probability is } \theta L / \bar{L} \\
1, \text { probability is } 1-\theta L / \bar{L}
\end{array}, \alpha=\left\{\begin{array}{l}
\bar{\alpha}, \text { probability is } \pi \\
1, \text { probability is } 1-\pi
\end{array}\right.\right.
$$

where $\bar{\omega}>1, \quad \bar{\alpha}<1$.

If the investment succeeds, then the maximum profit will be:

$$
\max _{y} \omega p y-\frac{1}{2} \alpha c y^{2}-r L W_{0}^{*}
$$

And the wealth of the enterprise at the time $t=2$ will be:

$$
W_{2}^{*}=\frac{p^{2}}{2 c}\left(\frac{\omega^{2}}{\alpha}-r L\right)
$$

When $t=2$ (Figure 1), if the investment fails, the enterprise must repay the bank. If the wealth is not adequate, it goes into bankruptcy. Then:

$$
W_{2}^{*}=0
$$


From (5) (6), when $t=2$ (Figure 1) the wealth of the enterprise will be:

$$
W_{2}^{*}=\max \left\{0, \frac{p^{2}}{2 c}\left(\frac{\omega^{2}}{\alpha}-r L\right)\right\}
$$

To make the problem meaningful/practical, there is an entailed assumption: whether open source or throttle effect takes place, the wealth is above 0 when $t=2$ (Figure 1 ), namely:

$$
\left\{\begin{array}{l}
\frac{\bar{\omega}^{2} p^{2}}{2 \bar{\alpha} c}-r L>0 \\
\frac{\bar{\omega}^{2} p^{2}}{2 \bar{\alpha}}-r L>0 \\
\frac{p^{2}}{2 \bar{\alpha} c}-r L>0
\end{array}\right.
$$

Then the maximum of wealth when $t=2$ (Figure 1 ) is

$$
\begin{gathered}
\max _{L} E W_{2}^{*}=\frac{p^{2}}{2 c} \frac{\theta L}{\bar{L}} \pi\left(\frac{\bar{\omega}^{2}}{\bar{\alpha}}-r L\right)+\frac{p^{2}}{2 c} \frac{\theta L}{\bar{L}}(1-\pi)\left(\bar{\omega}^{2}-r L\right)+\frac{p^{2}}{2 c} \pi\left(1-\frac{\theta L}{\bar{L}}\right)\left(\frac{1}{\bar{\alpha}}-r L\right) \\
\max _{L} E W_{2}^{*}=\theta L \pi\left(\frac{\bar{\omega}^{2}}{\bar{\alpha}}-r L\right)+\theta L(1-\pi)\left(\bar{\omega}^{2}-r L\right)+\pi(\bar{L}-\theta L)\left(\frac{1}{\bar{\alpha}}-r L\right)
\end{gathered}
$$

Solve the first-order condition,

$$
2(1-\pi) \theta r L=\pi \theta \frac{\bar{\omega}^{2}}{\bar{\alpha}}-\pi r \bar{L}-\pi \theta \frac{1}{\bar{\alpha}}+\theta \bar{\omega}^{2}-\pi \theta \bar{\omega}^{2}
$$

So the optimal loan is

$$
L=\frac{\pi \theta\left(\frac{\bar{\omega}^{2}}{\bar{\alpha}}-\frac{1}{\bar{\alpha}}\right)+\theta \bar{\omega}^{2}(1-\pi)-\pi r \bar{L}}{2(1-\pi) \theta r}
$$

Then, the comparative static analysis of the above formula:

1) $\bar{\alpha} \downarrow$, then $L \uparrow . \alpha$ is the factor of throttle effect. So the lower its value is, the greater the effect becomes, and more cost the enterprise will save. In this way, the enterprise may increase investment and try to realize technology innovation.

2) $\bar{\omega} \uparrow$, then $L \uparrow$. Similar to the first one, $\omega$ is the factor of open source effect. The higher its value becomes, the higher the product price and enterprise profit will be, which encourages bigger investment.

3) $r \uparrow$, then $L \downarrow$. Such a result shows if interest rate set by financial institution for the loan is high, it may restrain the driving force of enterprise technology innovation to some extent.

4) $\theta \uparrow$ or $\pi \uparrow$, then $\theta L \uparrow$ and $L \uparrow$. To some extent, $\theta$ is the efficiency factor of an innovation project, which shows the increase of probability of transformation in accordance to one unit increase of the loan. If technology gives the factors a positive elevation, then the enterprise should take the opportunity to transform as early as possible, so as to gain more profit.

From the analysis of model 1 , if there is no other financing channel but in- 
direct ones (of the banking system), interest rate of the loan, namely cost of the capital is one of the crucial factors to decide whether an enterprise will take technology innovation. When effect factor of open source and throttle is fix/set, the lower the cost is, the higher probability of transformation will be, and the higher motivation for enterprises to do so.

\section{Model 1e Simplified Benchmark Model}

Here, throttle effect is ignored for the sake of simplification (in fact, it can be regularized into open source effect). Then, regularize the unit of wealth. Take $p^{2} / 2 c$ as one unit of wealth, so the loan ratio $L$ in model 1 is equal to the amount of loan. Supposing there is only risk-free interest rates, then value model 1 with $r=r_{f}$. To further relax the hypothesis: loan for R\&D is not necessarily to be more than one unit, namely $r L \geq 1$ is not a required condition, then there is marginal space for enterprises to balance between a further struggle for R\&D or go bankruptcy.

If the enterprise chooses $L \leq 1 / r_{f}$, and marks it as $\kappa=\omega^{2} / \alpha$, then:

$$
\max _{L} \frac{\theta L}{\bar{L}}\left(\kappa-r_{f} L\right)+\left(1-\frac{\theta L}{\bar{L}}\right)\left(1-r_{f} L\right)
$$

By applying expectation operator:

$$
E[\kappa-1 \mid L=1]=\frac{\theta}{\bar{L}}(\kappa-1)
$$

The optimal loan should be:

If

$$
E[\kappa-1 \mid L=1]>r_{f}, \text { then } L^{*}=\frac{1}{r_{f}}
$$

If

$$
E[\kappa-1 \mid L=1]<r_{f} \text {, then } L^{*}=0
$$

If

$$
E[\kappa-1 \mid L=1]=r_{f}, \text { then } L^{*} \in\left[0,1 / r_{f}\right]
$$

If an enterprise chooses $L>1 / r_{f}$, it can receive a higher wealth expectancy (details can be found in the next model). However, from the lenders' perspective, if bankruptcy is allowed (when $t=3$ (Figure 1) if the enterprise does not succeed, nor can it repay principal and interest), then the lender can get only one unit of wealth. Apparently, this is no better than the risk-free asset invest (note that $r_{f}$ is always risk-free, so its value is always above 1). Formally, as $r_{f} L>1$, then:

$$
\theta_{L} r_{f} L+\left(1-\theta_{L}\right)<r_{f} L
$$

So it is impossible for the investor to permit the enterprise to go bankruptcy. Therefore if the rate is fixed, and the expected extra benefit brought by technology innovation is below that level, enterprise will not invest in innovation R\&D. For the countries under interest rate control, floating range of the benchmark interest rate exerts great influence upon enterprise decision on technology in- 
novation.

From model 1 and modelle, investment cost is the problem conSidered during decision making. If the cost is low and the expected return is higher than interest rate, enterprise will be motivated to engage in innovation. Still, the short-turn problem of how to reduce capital cost which caters to stock adjustment on the supply-side remains to be solved.

\section{Model 2: Indirect Financing Channels}

For a long time, the sum of bank loan has taken up above $90 \%$ of the total financing in China (Yi Li, 2011) [28]. So bank activity alone is the subject under discussion.

Base on the simplified model, investment in $\mathrm{R} \& \mathrm{D}$ is supposed to be $I=1+L$ with the implicit assumption $L \geq 0$. When $t=3$ (Figure 2), an enterprises get the result of investment. If succeeds, then:

$$
W_{3}=\frac{\omega^{2}}{\alpha}-r L
$$

As in model 1, $r$ represents aggregate rate. If innovation fail, then:

$$
W_{3}=\max \{1-r L, 0\}
$$

Combination of (18) and (19) shows that the bank needs to make out a loan contact: an enterprise proposes the expected amount of loan $L$, bank settles the rate $r$ accordingly. As information between the bank and the enterprise is asymmetric, the bank cannot predict the actual probability of the enterprise innovation, which leads to a variant $r$ when estimating innovation efficiency of the enterprise. One step further, if the bank knows the real value of $r$, but due to asymmetric information, the enterprise takes that the reciprocal of the estimation distributes in uniform, which is showed as follows:

$$
\frac{1}{\gamma} \sim U\left[1-\frac{(1-\tau)}{2} \Delta \gamma, 1+\frac{(1-\tau)}{2} \Delta \gamma\right]
$$

So it is marked as:

$$
\gamma^{e} \equiv E\left(\frac{1}{\gamma}\right)=1+\tau \Delta \gamma
$$

$\tau \Delta \gamma$ shows the degree of asymmetry between the two. If $\tau=0$, the enterprise takes the estimation of the bank as correct. Otherwise the innovation efficiency is thought to be underestimated $(\tau<0)$ or overestimated $(\tau>0)$. Apart from this, the bank may compare between the enterprise's R\&D loan $L$ and the

\begin{tabular}{lll}
$t=0$ & \multicolumn{1}{c}{$t=1$} &
\end{tabular}

Figure 2. The process of indirect finance support for enterprise innovation. 
weighted mean $\tilde{L}$ of other enterprises $(\tilde{L}<1)$, and form its own belief through probability estimation. Just like Jeremy Petranka (2000), the ratio form of contest success function (CSF) is applied here. If risk-free interest rate of the bank is marked as $r_{f}\left(r_{f} \geq 1\right.$, measuring the opportunity cost). There are two circumstances:

$L\left\{\begin{array}{l}L_{r_{f}} \leq 1 \text {, the bank chooses } r=r_{f} \text { to get risk-free return } \\ L_{r_{f}}>1 \text {, even for } r=r_{f} \text {, enterprise may go bankruptcy. So risk premium is needed. }\end{array}\right.$

( $L$ is the amount of loan chosen by the enterprise)

Situation One

If the R\&D loan satisfies $L \leq 1 / r_{f}$, the following condition also needs to be satisfied to attract the bank:

$$
\frac{\gamma \theta L}{\tilde{L}+\gamma \theta L} r L+\frac{\tilde{L}}{\tilde{L}+\gamma \theta L} r L \geq r_{f} L
$$

If the bank only wants to balance the expected return and opportunity cost, then:

$$
r=r_{f}
$$

When $t=1$, the optimal situation for the enterprise is:

$$
\begin{aligned}
L^{*} & =\arg \max _{L} \frac{\theta L}{\bar{L}}\left(\frac{\omega^{2}}{\alpha}-r_{f} L\right)+\left(1-\frac{\theta L}{\bar{L}}\right)\left(1-r_{f} L\right) \\
& =\arg \max _{L} \frac{\theta L}{\bar{L}} \frac{\omega^{2}}{\alpha}+\left(1-\frac{\theta L}{\bar{L}}\right)-r_{f} L
\end{aligned}
$$

So if mark $\kappa=\omega^{2} / \alpha$, the application of expectation operator will produce:

$$
E[\kappa-1 \mid L=1]=\frac{\theta}{\bar{L}}(\kappa-1)
$$

If

$$
E[\kappa-1 \mid L=1]>r_{f}, \text { then } L^{*}=1 / r_{f}
$$

If

$$
E[\kappa-1 \mid L=1]<r_{f} \text {, then } L^{*}=0
$$

If

$$
E[\kappa-1 \mid L=1]=r_{f}, \text { then } L^{*} \in\left[0,1 / r_{f}\right]
$$

Situation Two

If the enterprise asks for a loan $1>1 / r_{f}$, then it can only repay with wealth, so:

$$
\frac{\gamma \theta L}{\tilde{L}+\gamma \theta L} r L+\frac{\tilde{L}}{\tilde{L}+\gamma \theta L} \geq r_{f} L
$$

Which produces the result as:

$$
r=r_{f}+\frac{\tilde{L}}{\gamma \theta L}\left(r_{f}-\frac{1}{L}\right)
$$


When $t=2$, the maximum gaining reaped from the chosen loan will be:

$$
\begin{aligned}
\max _{L} E W_{3} & =\theta L\left[\frac{\omega^{2}}{\alpha}-E(r) L\right] \\
& =\theta L\left[\frac{\omega^{2}}{\alpha}-r_{f} L-\frac{\gamma^{e} \tilde{L}}{\theta L}\left(r_{f}-\frac{1}{L}\right) L\right]
\end{aligned}
$$

Solve the problem in (31), the optimal loan is:

$$
L^{*}=\frac{\omega^{2}}{2 \alpha r_{f}}-\frac{\gamma^{e} \tilde{L}}{2 \theta}
$$

According to Equation (32), when risk-free interest rate declines, the financing cost drops, and the rate of enterprise loan will increase. As the margin of profit $\kappa=\frac{\omega^{2}}{\alpha}$ after innovation applied increases, an enterprise will take the advantage of technology, expand its market share and reap profit from monopoly, and the loan will increases. If the enterprise thinks its innovation efficiency $\gamma$ is underestimated, it will add more loans. If R\&D loan $\tilde{L}$ of other enterprises increase, it will be difficult for an enterprise to get an advantage in technology R\&D through bank loan. At this time, an enterprise tends to safeguard its position and maintain industry barriers so as to stop other enterprise from entering the industry. Technology progress now is not the only focus, so it may reduce its loan.

A summary of the above analysis leads to the conclusion:

First, the curve of interest rate and loan composes risk-free interest rate and risk premium, which is formally presented in:

$$
r=r_{f}+\frac{\tilde{L}}{\gamma \theta L}\left(r_{f}-\frac{1}{L}\right)
$$

Risk premium is:

$$
\frac{\tilde{L}}{\gamma \theta L}\left(r_{f}-\frac{1}{L}\right)
$$

Second, in face of positive technology shock, namely when $\tilde{L}$ declines, the bank may take that enterprise default risk may be lower, so it reduces risk premium, which may motivate the enterprise to increase its loan in order to make a full use of technology shock.

\section{Model 2e: Direct Financing Channel}

Supposing an enterprise can raise fund from two markets: the banking system and the financing market, the amount is marked as $L_{1}$ and $L_{2}$ respectively. To simplify the problem, the bank makes a risk-free interest rate $r_{f}$, and asks the enterprise to be able payback the principal and interest (as called "safe loan"). Direct financing market does not ask a full payback of the principal and interest (like the stock market), but requires a risk premium $r_{p}>0$ to compensate for the risks it took. So the interest rate here is $i=r_{f}+r_{p}$. If the enterprise chooses "safe loan", the optimal loan an enterprise can get is $L_{1}^{*}$ and $L_{2}^{*}$, then: 


$$
\begin{gathered}
\max _{L_{1}, L_{2}} \frac{\theta L}{\bar{L}}\left(\kappa-r_{f} L_{1}-i L_{2}\right) \\
\text { s.t. }\left\{\begin{array}{l}
L=L_{1}+L_{2} \\
r_{f} L_{1}+i L_{2}>1 \\
r_{f} L_{1} \leq 1 \\
L_{1}>0, L_{2} \geq 0
\end{array}\right.
\end{gathered}
$$

The optimization in (35) is sure to have $r_{f} L_{1}=1$, or the cost of loan may increase (note $i>r_{f}$ ). Supposing there is interior point solution for an enterprise, the problem can be rewritten as:

$$
\max _{L_{2}} \frac{\theta\left(L_{2}+1 / r_{f}\right)}{\bar{L}}\left(\kappa-1-i L_{2}\right)
$$

So the first-order condition is:

$$
\frac{\theta}{\bar{L}}\left(\kappa-1-i L_{2}\right)-\frac{\theta\left(L_{2}+1 / r_{f}\right)}{\bar{L}} i=0
$$

There is a solution:

$$
L_{2}=\frac{\kappa-1}{2 i}-\frac{1}{2 r_{f}}
$$

According to (38), to make $L_{2}>0$, there must be:

$$
\kappa-1>\frac{i}{r_{f}}
$$

So $L_{1}=1 / r_{f}$ and (38) suggests:

$$
L_{1}+L_{2}=\frac{\kappa-1}{2 i}+\frac{1}{2 r_{f}}=\frac{(\kappa-1) r_{f}+i}{2 i r_{f}}
$$

Plug (39) into (40), then:

$$
L_{1}+L_{2}>\frac{1}{r_{f}}
$$

Comparison between the above and $r_{f} L_{1}=1$ shows funding invested in $\mathrm{R} \& \mathrm{D}$ significantly increases after direct financing market is introduced. Next is to test whether this optimal solution holds water, namely whether an enterprise under the optimal circumstance bears more expected wealth than that in the benchmark model. Plug (38), (40) into the target function of (35), then:

$$
\begin{aligned}
E W & =\frac{\theta\left[(\kappa-1) r_{f}+i\right]}{2 i r_{f} \bar{L}}\left(\kappa-1-i \frac{\kappa-1}{2 i}+\frac{i}{2 r_{f}}\right)=\frac{\theta\left[(\kappa-1) r_{f}+i\right]}{2 i r_{f} \bar{L}}\left(\frac{\kappa-1}{2}+\frac{i}{2 r_{f}}\right) \\
& =\frac{\theta}{r_{f} \bar{L}}\left[\frac{(\kappa-1)^{2} r_{f}^{2}+2(\kappa-1) r_{f} i+i^{2}}{4 i r_{f}}\right]=\frac{\theta}{r_{f} \bar{L}} \frac{\left[(\kappa-1) r_{f}+i\right]^{2}}{4 i r_{f}} \\
& \geq \frac{\theta}{r_{f} \bar{L}} \frac{4(\kappa-1) r_{f} i}{4 i r_{f}}=\frac{\theta}{r_{f} \bar{L}}(\kappa-1)
\end{aligned}
$$

The last one shows the expected wealth of an enterprise when only risk-free interest rate loan is available. If and only if $(\kappa-1) r_{f}=i$, will there be a solution for the last but second sign of inequality to make equal. So in order to motivate 
the enterprise to devote more funds for R\&D and support industry upgrading, the optimal financial structure should meet the requirement in (39), which shows if ratio between interest rate and risk-free interest rate is lower than the extra profit brought by technology innovation, direct financing channels (financial market) will promote enterprises to invest more in technological innovation.

Model 2 and model $2 \mathrm{e}$ reveals that if only direct financing channel is available, information asymmetry is the major cause of financing constraint, which may inhibit innovation R\&D of an enterprise. If both direct and indirect financing channels exist, introduction of the former may significantly increase investment in $R \& D$, which benefits innovation activities of an enterprise.

\section{Conclusions}

Supply-side structural reform focuses on self-regulation of the market. Since the enterprise is the main body of market, whether it runs well places a key role in supply-side reform. In the short term, the reform needs to cope with the problem of reducing capital cost. By adjusting the stock, enterprises that are capable and willing to participate in innovation activities are relieved from the pressure of high financing cost. Then they can participate again in starting up undertakings, becoming the micro-drive for economy development.

When making decisions for the investment, enterprises need to weigh on the expected return and investment cost. And the choice of financing channel is closely linked to the maximization of profit. Concerning the structural problem of China's supply side, government should push forward finical reform, build up a complete multi-level capital market, expand direct financing channels, and reduce financial transaction cost, so as to provide funds through a developed financial market. Government should also bring down the ratio of interest rate and risk-free interest rate, and encourage enterprises to conduct comprehensive innovation, so as to make it a new economic spin-off/growth point.

\section{References}

[1] Wu, M. (2016) What Is "Supply-Side Reform? The Best Explanation. Journal of Citizen Introduction, 1, 56-57.

[2] Liu, X.H. (2013) Macroeconomic Management on Supply Side: A Chinese Perspective. Economic Perspectives, 10, 9-19.

[3] Deng, L. and Du, S. (2015) Supply-Side Structural Reform: A New Force and Challenge. Theory \& Practice, 12, 18-20.

[4] Feng, Z.F. (2016) Theory and Practice of Supply-Side Structural Reform. On Economic Problems, 2, 12-17.

[5] Li, Z. and Yuan, J.F. (2015) Supply-Side Reform Plan Based on Economic Reality in China. Theory \& Practice, 12, 12-17.

[6] Xu, K.N. (2016) Several Problems and Policy Choice of Supply-Side Reform. Modern Economic Research, 4, 5-9.

[7] Hu, A.G., Zhou, S.J. and Ren, H. (2016) Supply-Side Structural Reform: Adaptation and Pioneer of China's Economic New Normal. Journal of Tsinghua University (Philosophy and Social Science), 2, 17-23. 
[8] Li, C. (2016) Theoretical Support and Policy Choice of Supply-Side Reform. Comparative Economic \& Social System, 1, 9-18.

[9] Wang, H.J. and Wang, C. (2016) International Economic Cycle Mismatch, SupplySide Reform and Medium-High Rate of Economic Growth in China. Finance \& Trade Economics, 2, 5-19.

[10] Lin, W.B. and Su, J. (2016) Essence and Implementation of Supply-Side Reform. Theory \& Practice, 1, 16-19.

[11] An, Y. (2016) Supply-Side Reform. Macroeconomic Management, 1, 84-84.

[12] Aghion, P. and Howitt, P. (1991) Unemployment: A Symptom of Stagnation or a Side-Effect of Growth? European Economic Review, 35, 535-541.

[13] Romer, D. (1990) Staggered Price Setting with Endogenous Frequency of Adjustment. Economics Letters, 32, 205-210.

[14] Hall, B.H. and Lerner, J. (2001) The Financing of R\&D and Innovation. Handbook of the Economics of Innovation, 1, 609-639.

[15] Hall, P. (1992) Convergence Rates in the Central Limit Theorem for Means of Autoregressive and Moving Average Sequences. Stochastic Processes and Their Applications, 42, 115-131.

[16] Dixit, A.K. and Pindyck, R.S. (1998) The Options Approach to Capital Investment. Volume 1, Massachusetts Institute of Technology Press, Cambridge, 325-340.

[17] Pindyck, R.S. (1993) Investments of Uncertain Cost. Journal of Financial Economics, 34, 53-76.

[18] Harhoff, D. and Körting, T. (1998) Lending Relationships in Germany-Empirical Evidence from Survey Data. Journal of Banking \& Finance, 22, 1317-1353.

[19] Takalo, T., Tanayama, T. and Toivanen, O. (2013) Market Failures and the Additionality Effects of Public Support to Private R\&D: Theory and Empirical Implications. International Journal of Industrial Organization, 31, 634-642.

[20] Saint, P. (1992) Technological Choice, Financial Markets and Economic Development. European Economic Review, 4, 763-781.

[21] Benfratello, L., Schiantarelli, F. and Sembenelli, A. (2008) Banks and Innovation: Microeconometric Evidence on Italian Firms. Journal of Financial Economics, 90, 197-217.

[22] Fama, E.F. and Jensen, M.C. (1985) Organizational Forms and Investment Decisions. Journal of Financial Economics, 14, 101-119.

[23] Datta, S., Iskandar-Datta, M. and Patel, A. (1999) Bank Monitoring and the Pricing of Corporate Public Debt. Journal of Financial Economics, 51, 435-449.

[24] Berger, A.N. and Udell, G.F. (1990) Collateral, Loan Quality and Bank Risk. Journal of Monetary Economics, 25, 21-42.

[25] Chen, S., Sun, Z., Tang, S. and Wu, D. (2011) Government Intervention and Investment Efficiency: Evidence from China. Journal of Corporate Finance, 17, 259271.

[26] He, G. and Chang, X. (2011) Study on Independent Innovation Capacity Supported by Indirect Financing in Various Regions of China. Investment Research, 11, 16-28.

[27] Ye, Y. and Wang, S. (2007) Empirical Analysis about the Promotion Effect of Financing Intermediation on Technological Innovation. Commercial Research, 8, 106-111.

[28] Li, Y. and Li, K. (2011) Analysis of the Obstacles to the Financing of Innovative Enterprises in China. Modern Business Trade Industry, 1, 156-157. 
Submit or recommend next manuscript to SCIRP and we will provide best service for you:

Accepting pre-submission inquiries through Email, Facebook, LinkedIn, Twitter, etc. A wide selection of journals (inclusive of 9 subjects, more than 200 journals)

Providing 24-hour high-quality service

User-friendly online submission system

Fair and swift peer-review system

Efficient typesetting and proofreading procedure

Display of the result of downloads and visits, as well as the number of cited articles Maximum dissemination of your research work

Submit your manuscript at: http://papersubmission.scirp.org/

Or contact jss@scirp.org 